\title{
A Comparison of Variations of Prompt Delay During Instruction on an Expressive Labeling Task
}

\author{
Sean J. O'Neill ${ }^{1}$. Claire McDowell ${ }^{2}$. Julian C. Leslie ${ }^{2}$ (1) \\ Published online: 4 September 2020 \\ (c) The Author(s) 2020
}

\begin{abstract}
Variations in prompt delay procedures are used in discrete-trial training to reduce the occurrence of errors before task mastery. However, the variations are seldom compared systematically. Using an adapted alternating treatments design, the present study compared progressive prompt delay with 2-s or 5-s constant prompt delay, on the acquisition of an expressive labeling task in four participants with autism spectrum disorder and intellectual disability. While all three prompt delay methods led to mastery of the tasks, albeit only when the tasks were simplified for one participant, progressive prompt delay generally proved the most efficient method on several measures, including lower error rates. This is consistent with the nature of the progressive prompt delay procedure which allows less time for errors to occur early in training. It is provisionally concluded that selection of progressive prompt delay is supported as a wise first choice option for clinicians, as a history of high error rates may impair later learning.
\end{abstract}

Keywords Autistic spectrum disorder · Expressive labeling · Prompt delay · Adapted alternating treatment design

Julian C. Leslie

jc.leslie@ulster.ac.uk

Sean J. O'Neill

s.j.oneill@qub.ac.uk

Claire McDowell

ce.mcdowell@ulster.ac.uk

1 School of Medicine, Dentistry \& Biomedical Sciences, Queen's University, Belfast, Northern Ireland, UK

2 School of Psychology, Ulster University, Coleraine, Northern Ireland BT52 1SA, UK 


\section{Introduction}

Common problems encountered during instruction can relate to behavioral skills deficits, low motivation to learn, poor stimulus control, limited generalization, or behavioral excesses. Such problems are barriers to learning that can negatively impact the independence of individuals with autism spectrum disorder (ASD) and/ or intellectual disability (ID), restricting their ability to achieve meaningful outcomes (Hanley et al. 2003; Odom and Strain 2002). Prompting strategies are integral components of instructional programs for individuals from these populations. An instructor may use prompts to evoke a desired response during initial instruction. After the learner has met a predetermined level of accuracy, the instructor will then systemically fade the prompts to facilitate independent responding by the individual.

There are many types of prompt-fading procedures available to instructors (See Green 2001, for a review). Prompt delay ${ }^{1}$ (Coleman-Martin and Heller 2004; Halbur et al. 2019; Heal et al. 2009; O'Neill et al. 2018; Reichow and Wolery 2011) uses a delay interval to 'fade out' or transfer stimulus control from the prompt to the natural discriminative stimulus $\left(\mathrm{S}^{\mathrm{D}}\right)$ intrinsic to the skill under instruction (Snell 1982; Snell and Gast 1981; Touchette 1971; Touchette and Howard 1984), and allows for independent responding to emerge.

Conditional discriminations are essential in functional and academic skills commonly taught in behavioral interventions for individuals with ASD/ID (Fisher et al. 2019; Green 2001). Conditional discriminations contain four components: (1) a contextual or conditional stimulus; (2) a discriminative stimulus $\left(\mathrm{S}^{\mathrm{D}}\right)$ indicating that reinforcement is available given a response; (3) a response; and (4) a consequence. This type of training requires learners to respond differentially to nonidentical but related stimuli when accompanied or preceded by a certain antecedent stimulus. An example of this is holding a blue card up (conditional stimulus) to a learner, asking 'what's this' $\left(\mathrm{S}^{\mathrm{D}}\right)$ the learner saying 'blue' (response), and verbal praise, 'well done,' being delivered as a consequence.

Prompting is often necessary for individuals with ASD/ID as verbal instructions may be insufficient to evoke a target response. Prompt delay procedures are adaptable and may be used in conditional discrimination training. The initial set of trials in a prompt delay procedure begins by providing a conditional stimulus followed by presentation of the $\mathrm{S}^{\mathrm{D}}$ along with an added prompt to evoke the target response. This is known as zero-second or simultaneous prompting and functions to reduce the probability of a learner error. Subsequently, the prompt is delayed by an interval of time allowing for an independent correct response to occur. Progressive and constant prompt delay procedures differ at this point (Walker 2008). In progressive prompt delay, the prompt is delayed by small intervals of time that increase incrementally (e.g., $1 \mathrm{~s}$, then $2 \mathrm{~s}$, up to a maximum value, in this case $5 \mathrm{~s}$ ) between instructional sessions, with increases in delay to the prompt being contingent on

\footnotetext{
1 "Prompt delays" are more often termed "time delays". However, as it is the delivery of the prompt that varies in time, the former term is more appropriate (see Fisher et al. 2019; National Autism Center 2015; O’Neill et al. 2018).
} 
learners performance. Alternatively, in the constant prompt delay procedure the prompt is delayed by the same interval of time in each session that includes prompts. With either procedure, prompts remain until a mastery criterion is achieved.

The scheduled delay of a prompt allows time for the learner to make an independent response, but if this is not made, the prompt occurs. This is an important feature of prompt delay, as without these prompting sequences repeated errors may occur and may hinder subsequent learning when more effective procedures are introduced. Cengher et al. (2016), among others (Coon and Miguel 2012; Etzel and LeBlanc 1979; Roncati et al. 2019; Schilmoeller et al. 1979), provide evidence for the role of instructional history in hindered skill acquisition. In their study, learning targets assigned to the control condition and least efficient instructional procedure (least to most; LTM) were subsequently taught with the most effective and efficient procedure (most to least; MTL). At this stage, three out of four participants acquired the targets previously assigned to the control condition, but no participant mastered targets previously taught with the least efficient condition. The Coon and Miguel (2012) and Roncati et al. (2019) studies provide evidence for increasingly efficient acquisition of instructional targets when following a recent history of instruction with those same prompt types, as compared with other prompt types. This lends support to the importance and influence of recent instructional history on subsequent instructional performance. In behavior analytic practice, if an instructional strategy proves ineffective, then a different instructional procedure is implemented. These findings direct us to the importance of selecting procedures most likely to be effective and efficient first.

The efficacy of prompt delay is reported in several reviews (Cengher et al. 2018, 2019; Demchak 1990; Handen and Zane 1987; Walker 2008; Wolery et al. 1992) and is supported as an evidence-based intervention in the literature related to a wide range of problems and contexts (National Autism Center 2009, 2015; Wong et al. 2015). However, reviews of this evidence tend to group progressive and constant prompt delay together, making broad recommendations for their use despite their procedural differences. This is true of the Wong et al. (2015) and National Autism Center's (2009) reviews, and is presumably due to the scarcity of published work to have compared variations of prompt delay directly (Ault et al. 1988; O'Neill et al. 2018). However, Libby et al. (2008) did compare three prompting procedures, one of which involved delay. These were most to least (MTL) prompting, least to most (LTM) prompting, and MTL with a delay (MTLD). They found that acquisition for the three participants was nearly as rapid in MTLD as LTM, but MTLD produced fewer errors than LTM, with MTL producing the slowest acquisition. High error rates may lead to the emission of responses that function to escape difficult, error-prone tasks (Carr and Durand 1985; Heckaman et al. 1998; MacDuff et al. 1993; Schilmoeller et al. 1979; Weeks and Gaylord-Ross 1981) and reduce contact with reinforcement contingencies. A major objective of prompt delay is to move toward errorless learning, which has been shown to be possible with pigeons (Terrace 1963), first-grade children (Robinson and Storm 1978), children with ASD and/ or ID (Ault et al. 1988; O'Neill et al. 2018), and adults with ID (Touchette 1968, 1971). The argument is that an errorless procedure will ensure that contact is maintained with the contingencies in the early stages of training. 
To date only two published studies have directly compared variations of prompt delay. Ault, Gast, and Wolery (1988) used both an 8-s progressive prompt delay and a 5-s constant prompt delay procedure with three learners with moderate ID when learning a community sign-reading task. Both variations of prompt delay were effective, with the 5-s constant prompt delay procedure shown to be marginally more efficient than the progressive prompt delay procedure. Results did not conclusively favor one procedure over the other in this study, with replication recommended. More recently, O'Neill et al. (2018) have attempted a partial replication, comparing three variations of prompt delay (2-s or 5-s constant prompt delay, and 5-s progressive prompt delay) with trial-and-error instruction on a receptive conditional discrimination task. A procedural modification, in the form of differential reinforcement, was added to prompt delay for two of the four participants. With or without this procedural modification, results suggested progressive prompt delay was effective and most efficient in reducing learner errors during instruction. Mixed outcomes are not uncommon in comparison studies and may be due, in part, to methodological differences (Cengher et al. 2018; Wolery et al. 1992). Although one further study did compare constant with progressive prompt delay and reported that overall progressive prompt delay resulted in fewer errors, instructional time, and sessions to criterion, this was an unpublished master's thesis (Thomas 1989, cited in Wolery et al. 1992), and there is a lack of consensus among the two published comparison studies reviewed above. Given the importance of having evidence for selecting the most effective and efficient instructional procedure first (Cengher et al. 2016; Coon and Miguel 2012; Etzel and LeBlanc 1979; Roncati et al. 2019; Schilmoeller et al. 1979), a further comparison was made in the present study.

This study used an adapted alternating treatments design to compare three variations of the prompt delay procedure (2-s or 5-s constant prompt delay and 5-s progressive prompt delay), with a control condition, on measures of effectiveness and efficiency when teaching an expressive labeling task to learners with ASD and ID. The research questions were: (1) which of these conditions were effective? (2) Which could prove most efficient in terms of trials to criterion, errors to criterion, and duration of instruction, with this client group?

\section{Method}

\section{Participants and Setting}

The four participants, three males and one female, attended a special education school that was purpose built for learners with severe, profound and multiple learning difficulties of both primary and secondary school age. Participants attended $5.5 \mathrm{~h}$ per day, 5 days per week, 9 months of the year and ranged between 11.6 and 18.4 years and had Expressive Vocabulary Test-2 (EVT $\left.{ }^{\mathrm{TM}}-2\right)$ scores across the range of 3.11 to 9.9 years. The EVT-2 is a norm-referenced standardized test used to assess expressive language (Williams 2007). For inclusion, participants had been independently diagnosed with an ASD and/or ID in the severe range, were able to attend to a tabletop task for approximately $10 \mathrm{~min}$, and could imitate an echoic 
Table 1 Participant information

\begin{tabular}{llllll}
\hline Name & Sex & Age (year:month) & $\begin{array}{l}\text { EVT (A) score } \\
\text { (year:month) }\end{array}$ & Age minus EVT & Diagnosis $^{\mathrm{a}}$ \\
\hline Seamus & M & 14.4 & 9.9 & 4.7 & SLD $^{\mathrm{b}}+\mathrm{ASD}^{\mathrm{c}}$ \\
Cian & M & 11.6 & 4.9 & 6.9 & SLD $^{\text {ASD }}$ \\
Cahil & M & 13.7 & 3.11 & 9.8 & SLD + ASD \\
Eimear & F & 18.4 & 5.2 & 13.2 & SLD + ASD \\
\hline
\end{tabular}

${ }^{\mathrm{a}}$ Difference between chronological age and EVT score (EVT $\left.{ }^{\mathrm{TM}}-2\right)$

${ }^{\mathrm{b}}$ Severe learning difficulty

${ }^{\mathrm{c}}$ Autism spectrum disorder

verbal prompt within 3-5 s of delivery. Participants had not been exposed to the stimuli that were used for training (country flags), and had no history of training with delayed prompting procedures or other systematic prompting procedures commonly used in behavioral interventions. All participants were native English speakers. Consent to conduct this experiment was granted by the University's Research Ethics Committee, and informed consent and assent were obtained from the participants' parents and participants themselves, respectively. Table 1 contains participant information (name, gender, age, EVT-2, difference between age and EVT-2 score, and diagnosis). Experimental sessions were conducted in a small classroom adjoining the main classroom. This room was used by all students for one-to-one instruction with a teaching assistant from time to time as it provided minimal distractions from educational tasks. During experimental sessions, participants were seated at a table beside the experimenter; no other students were present during these sessions.

\section{Materials}

As the host school required educationally relevant materials to be used in the study, advice was taken from teachers about which instructional materials to use. Based on this, sets of 12 multi-colored country flags were devised. Flags were individually printed and laminated onto $16 \mathrm{~cm} \times 12 \mathrm{~cm}$ flash cards. Four sets of three flags were randomly assigned to the experimental conditions described below, with assignments differing across participants. A logical analysis (Gast 2009) was used to equalize stimulus set difficulty. Dimensions logically analyzed were: (a) number of colors per flag (maximum of three), (b) similarities of colors and featured lines, (c) number of symbols within a flag set, (d) number of vocal verbal country syllables (maximum of three), and (e) only those countries with names participants could verbally imitate were included. Flags were presented in isolation to participants by holding them approximately $30 \mathrm{~cm}$ in front of each participant, at their eye level. Presentation order was determined according to a quasi-randomized sequence determined by a standardized data recording sheet. Predetermined reinforcers, data collection sheet, and a token board were used during experimentation. The token board enabled 9 tokens, shaped as footballs, to be attached with Velcro when earned by a participant. 


\section{Dependent Measures}

Responses were recorded in one of the five possible ways at the conclusion of a trial. Independent correct or incorrect responses were scored dichotomously. These were defined as the participant emitting a verbal response that closely matched the name of the sample stimulus (+; country flag) or a verbal response that did not correspond to the sample stimulus (-), respectively. Prompted correct responses $(+p)$ or incorrect prompted responses $(-p)$ were defined in the same manner as outlined above with the inclusion of an echoic prompt delivered prior to the emission of a response. Failures to respond at all were recorded ( $\mathrm{NR}=$ no response). Errors were also recorded but had no programmed consequences and signaled the end of a trial.

Direct comparisons between instructional conditions were made using effectiveness and efficiency data. Effectiveness was defined as an instructional condition producing responding to mastery criterion level. Mastery criterion was defined as eight or nine $(>89 \%)$ independent or prompted correct responses $(+$ or $+p)$ made on three consecutive sessions inclusive of one 'no prompt' posttest session. A posttest session was conducted in the same manner as baseline (see below). Due to criteria used to move between prompting levels across sessions, prompting could only have occurred in the first of three consecutive sessions used to assess for mastery. Efficiency measures included: number of training trials, number of errors, percentage of errors to criterion, and instructional duration. Duration was a measure of time taken to carry out an instructional condition from beginning until mastery was attained. Recording began immediately prior to the experimenter gaining eye contact with the participant and ended when the last token was placed on the token board, signaling the end of the session.

\section{Experimental Design}

A within-subject-adapted alternating treatments design was used to examine four experimental conditions simultaneously, targeting non-reversible behaviors, with a focus on delineating relative efficiencies (Sindelar et al. 1985). This allowed for a direct comparison using effectiveness and efficiency measures across baseline and instructional phases.

\section{Procedure}

\section{Pre-baseline Assessment}

Prior to commencement, potential reinforcers were initially determined through teacher nomination and then by preference assessments of participant choice using a multiple stimulus without replacement protocol (DeLeon and Iwata 1996). Potential reinforcers used in the preference assessments included a range of edibles and time in a soft play area. 
Additionally, all participants underwent a screening of their ability to verbally imitate an echoic prompt (country names) from a list of potential training stimuli for use in the expressive labeling task. A list of 30 countries' names, each with a maximum of three syllables, was compiled. Stimuli successfully imitated by the participant were retained within a bank of potential training stimuli, and those that were not imitated were excluded. The verbal country name and flag were never paired at this stage.

\section{Baseline}

One or two baseline sessions, consisting of nine trials per session, occurred for each of the stimulus sets to ensure training materials were novel and equally difficult. (This was established as indicated by $0 \%$ correct responding reported in Results.) A baseline trial consisted of a sequence of nine components. The sequence was: (a) establish eye contact; (b) hold up sample stimulus; (c) experimenter says 'touch this'; (d) participant touches sample card with index finger (the differential observing response); (e) experimenter says 'what's this?'; (f) await learner response (up to $8 \mathrm{~s}$ ); (g) provide contingent reinforcement if appropriate (in practice, there were no correct responses in these sessions); (h) remove materials; and (i) observe a 3- to 5-s inter-trial interval.

\section{Instruction}

An instructional trial included 10 components: (a) establish eye contact; (b) hold up sample stimulus; (c) experimenter says 'touch this'; (d) secure a differential observing response; (e) experimenter says 'what's this'; (f) provide echoic prompt according to prompt level and condition, (g) await learner response (up to $8 \mathrm{~s}$ ); (h) provide contingent reinforcement if appropriate with a token on FR1 schedule; (i) remove materials; and (j) observe a 3- to 5-s inter-trial interval. During instruction for all conditions, prompted and independent correct responses both resulted in immediate verbal praise and token delivery. When three tokens were earned, the experimenter indicated to the participant that they could be exchanged for an edible or access to an activity at the end of the session (FR3 exchange schedule).

Four sessions were conducted daily, two in the morning and two in the afternoon, one from each of the conditions, 5-s progressive prompt delay (5-s PPD), 5-s constant prompt delay (5-s CPD), 2-s constant prompt delay (2-s CPD), and control. (While the inclusion of an additional 2-s PPD condition may have been useful, it was omitted to restrict the total number of conditions in the design.) All instruction sessions contained nine trials from the designated condition. Sessions were conducted on a one-to-one basis by the first author. Sessions were separated from each other by a minimum of $15 \mathrm{~min}$. Condition order of presentation was quasi-randomly determined prior to the experiment. Prompt levels used across conditions are shown in Table 2. All instructional conditions began with zero-second prompting. A zerosecond delay level trial contained components (a) through (j), outlined above. At step (f), following the experimenter saying, 'what's this?,' the experimenter immediately provided an echoic prompt $(\mathrm{S}+)$. Thereafter, instructional conditions differed. 
Table 2 Prompt levels for each instructional condition, progressive prompt delay (PPD) or constant prompt delay (CPD), and a control condition

\begin{tabular}{lllll}
\hline Prompt Level & 5-s PPD & 5-s CPD & 2-s CPD & Control \\
\hline Level 0 & 0-s delay & 0-s delay & 0-s delay & No prompt \\
Level 1 & 1-s delay & 5-s delay & 2-s delay & \\
Level 2 & 2-s delay & No prompt & No prompt & \\
Level 3 & 3-s delay & & & \\
Level 4 & 4-s delay & & & \\
Level 5 & 5-s delay & & & \\
Posttest & No prompt & No prompt & No prompt & No prompt \\
\hline
\end{tabular}

In 5-s PPD, the prompt delay was increased (across sessions) by 1-s increments up to a maximum of $5 \mathrm{~s}$. For example, at level 1 at step (f) the experimenter waited $1 \mathrm{~s}$ before delivering an echoic prompt, but at level 2 a 2 s delay was used, and so on. In 5-s CPD, a constant delay of $5 \mathrm{~s}$ was used at that point throughout training. In 2-s $\mathrm{CPD}$, a constant delay of $2 \mathrm{~s}$ was used throughout training. The control condition was an extension of baseline. No prompting was provided, but token reinforcement was available on an FR1 schedule for all correct independent responses. Instruction continued until the mastery criterion was met for each condition. When mastery had been achieved for a condition, instruction sessions continued with the remaining conditions. Once mastery had been reached for all three prompt conditions, instruction ceased. Maintenance probes were conducted at 2 and 4 weeks for one participant. These sessions followed the same protocol as that outlined above for baseline.

\section{Prompting Levels}

Criteria to move between the prompting levels of a condition were as follows: If eight or nine independent or prompted correct responses occurred in one session, the level was increased for the next session, and if two consecutive errors, or a total of three or more errors, occurred in one session, the prompt level was decreased for the next session. A 'no prompt' posttest session followed the protocol described for baseline.

\section{Inter-observer Agreement (IOA) and Procedural Integrity (PI)}

Observers independent of this research retrospectively analyzed IOA and PI (Billingsley et al. 1980). This was done in $33 \%$ of sessions, across participant conditions. Prior to IOA and PI analysis, observers underwent training where they reviewed 3-5 recorded experimental practice sessions with the first author. The first author scored each session pointing out the operationally defined steps contained in each. Observers then watched and scored practice sessions independently until they scored above $89 \%$ accuracy across two consecutive training sessions before moving on to scoring experimental sessions. The point-by-point method was used to calculate IOA for responses recorded (Ayres and Gast 2009). This was done by dividing the 
number of agreements by the number of agreements plus disagreements and multiplying by 100 . Agreement averaged $98.6 \%$ (range $77-100 \%$ ) across participants. PI was calculated by dividing the number of completed instructional trial components by the number of planned trial components and multiplying by 100 . Average PI score was $93.6 \%$ (range 33-100\%) across participants. The wide range (and slightly lower average) of PI scores came about because of disagreements in scores for one participant.

\section{Results}

The main study aims were to determine the effectiveness and relative efficiency of each instructional condition. Effectiveness will be reviewed first and then various efficiency measures. As shown in Fig. 1, all three instructional conditions were effective at producing mastery level performance in correct independent responses for all four participants. As this was an expressive language task, it was not surprising that on this measure all participants were unable to name any of the flags and scored zero in baseline sessions, indicating potential equal difficulty of the stimulus sets used. Once instruction started, performance improved in all three prompt delay conditions but not in the control condition. For three participants, mastery was reached soonest in the 5-s PPD condition. For the other participant, the task was simplified after session 53 because of slow progress, and then, mastery was reached soonest in the 2-s CPD condition.

Looking at effectiveness with individuals, Fig. 1 shows that for Seamus acquisition was rapid for the 5-s PPD condition with an immediate rise to mastery criterion level (8/9) in Session 3. Although this dropped to 7/9 in Session 4 it recovered in Session 5 to $9 / 9$ (100\%), maintaining this level for two additional sessions, inclusive of a posttest, to achieve mastery. 5-s PPD ranked first with mastery criterion attained in 63 training trials, The 5-s and 2-s CPD conditions followed, ranked second (90 trials) and third (117 trials), respectively. At this point, maintenance probes were run for all three prompt delay conditions. In all, 117 trials were run in the control condition with 108 (92.3\%) errors. Interestingly, the control condition encountered a threat to internal validity. During the latter quarter of the experiment, a different classroom of the school displayed a map of the world in which one of the country flags assigned to the control condition was shown; this name was taught and Seamus learned this name, resulting in three independent correct responses over the final three consecutive sessions. Following discovery of the classroom display, the experimenter confirmed that no other stimuli had been compromised and that no further flag training would occur before the conclusion of the study.

Cian also achieved mastery in all three instructional conditions. Following baseline, a steady upward acquisition trend was observed across all his conditions with no return to zero-second prompting following the first session. The 5-s PPD condition was ranked first with mastery achieved in 108 training trials; ranked second was the 2-s CPD condition with 117 training trials; ranked third was the 5-s CPD condition with 144 trials. In total, 144 trials were run in the control condition with 144 $(100 \%)$ errors. 

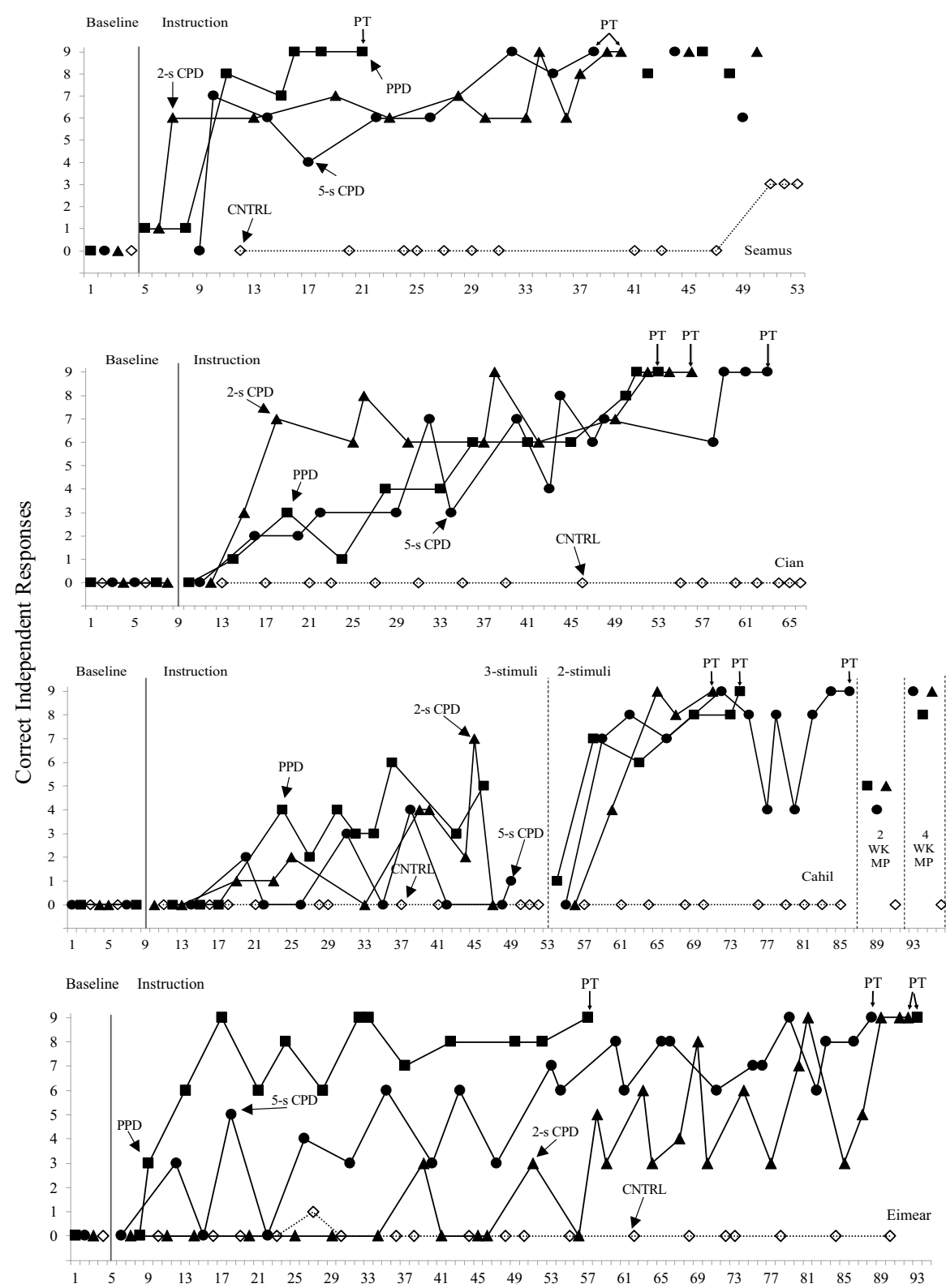

Fig. 1 Number of correct independent responses in successive sessions, for four participants with three prompt delays, progressive prompt delay (PPD, black squares), 2-s constant prompt delay (CPD 2-s, black triangles), 5-s constant prompt delay (5-s CPD. black circles), or control (open diamonds) conditions. When mastery criterion was met, a posttest (PT) was conducted. For Cahil, 3-stimuli instruction was changed to 2-stimuli instruction, and maintenance probes (MP) were conducted several weeks (WK) after final PT 
As with the other participants, Cahil initially underwent training with stimulus sets containing three flags assigned to each condition, but this participant's performance was characterized by considerable variability throughout training. Following 99 trials with no clear indication of an upward trend toward acquisition, training was altered, and stimulus training sets were reduced from three to two and training continued. This is denoted with a condition change line in Fig. 1. Following this change, a clear upward trend toward mastery criterion was seen in all of his conditions. Ranked first was the 2-s CPD condition with 45 trials; second was the 5-s PPD condition with 54 training trials; third was the 5-s CPD condition with 108 training trials. At 2 weeks post-acquisition, Cahil's performance fell to below the mastery criterion level; at 4 weeks post-acquisition, it then returned to within mastery criterion range $(\geq 8 / 9+)$ for the three probed conditions. A total of 198 trials were run in the control condition, with 198 (100\%) errors.

Eimear's performance is characterized by moderate variability between data points in each of her instructional conditions. This was indicative of a prolonged acquisition phase, with Eimear undergoing the most training trials overall (603; this compared with Seamus 270, Cian 369, and Cahil, 495). Despite this, mastery criterion was achieved, first in the 5-s PPD condition with 117 trials; ranked second was the 5-s CPD condition with 225 training trials; ranked third was the 2-s CPD condition with 261 trials. Control conditions were carried out for 171 trials with 170 (99.4\%) errors.

In summary, training was effective in all three instructional conditions for all four participants. The trials to mastery criterion given above are one measure of efficiency. Other measures are the number of errors before criterion was reached and the time taken (duration) for each condition. All three efficiency measures are shown in Table 3. These show that for the three participants trained throughout with 3-stimuli instruction, 5-s PPD was ranked first in trials to mastery, while for the other participant (Cahil) they were ranked 2-s CPD, then 5-s PPD, and then 5-s CPD. In terms of errors made, or percentage errors, 5-s PPD also produced the fewest errors for all four participants. Table 3 also shows the total duration of training for each instructional condition, and for three participants, the shortest time was recorded for the condition in which fewest trials to mastery were required (the exception was Cian).

Average performances are shown in Figs. 2 and 3. Figure 2 indicates the mean trials to criterion and percentages of errors to criterion for each instructional condition, with 5-s PPD having the lowest number of trials and the smallest percentage of errors. Figure 3 plots the mean instructional duration, and again, the 5-s PPD condition has the lowest value. Although there is variation across participants, the consistent overall pattern that emerges is of a typical advantage of 5-s PPD over the other instructional conditions. 
Table 3 Effectiveness and efficiency data for four participants across three instructional conditions, progressive prompt delay (PPD) or constant prompt delay (CPD), and a control condition (baseline data are excluded)

\begin{tabular}{|c|c|c|c|c|c|c|}
\hline Participant/condition & No. of training trials & Total errors & $\%$ errors & Duration & Rank & Mastery \\
\hline \multicolumn{7}{|l|}{ Seaтия } \\
\hline 5-s PPD & 63 & 2 & $3.2 \%$ & $00: 12: 55$ & 1 & Yes \\
\hline 5-s CPD & 90 & 6 & $6.7 \%$ & $00: 16: 33$ & 2 & Yes \\
\hline 2-s CPD & 117 & 9 & $7.7 \%$ & $00: 21: 40$ & 3 & Yes \\
\hline Control & 117 & 108 & $92.3 \%$ & & & No \\
\hline Total/average & $270^{\mathrm{a}}$ & $17^{\mathrm{a}}$ & $5.8 \%^{\mathrm{a}}$ & 00:51:08 & & \\
\hline \multicolumn{7}{|l|}{ Cian } \\
\hline 5-s PPD & 108 & 1 & $0.9 \%$ & $00: 32: 32$ & 1 & Yes \\
\hline 5-s CPD & 144 & 7 & $4.9 \%$ & $00: 43: 37$ & 3 & Yes \\
\hline 2-s CPD & 117 & 5 & $4.3 \%$ & 00:29:39 & 2 & Yes \\
\hline Control & 144 & 144 & $100 \%$ & & & No \\
\hline Total/average & $369^{\mathrm{a}}$ & $13^{\mathrm{a}}$ & $3.3 \%^{\mathrm{a}}$ & $01: 45: 48$ & & \\
\hline \multicolumn{7}{|l|}{ Cahil } \\
\hline 5-s PPD & $153(54)^{\mathrm{b}}$ & $16(0)^{\mathrm{b}}$ & $10.5 \%(0 \%)^{\mathrm{b}}$ & $00: 42: 12$ & 2 & Yes \\
\hline 5-s CPD & $198(108)^{\mathrm{b}}$ & $38(10)^{\mathrm{b}}$ & $19.2 \%(9.2 \%)^{\mathrm{b}}$ & $00: 50: 31$ & 3 & Yes \\
\hline 2-s CPD & $144(45)^{\mathrm{b}}$ & $26(1)^{\mathrm{b}}$ & $18.1 \%(2.2 \%)^{b}$ & $00: 38: 11$ & 1 & Yes \\
\hline Control & 198 & 198 & $100 \%$ & & & No \\
\hline Total/average & $495^{\mathrm{a}}(207)^{\mathrm{b}}$ & $80^{\mathrm{a}}(11)^{\mathrm{b}}$ & $15.9 \%^{\mathrm{a}}(3.8 \%)^{\mathrm{b}}$ & $02: 10: 54$ & & \\
\hline \multicolumn{7}{|l|}{ Eimear } \\
\hline 5-s PPD & 117 & 6 & $5.1 \%$ & $00: 24: 13$ & 1 & Yes \\
\hline 5-s CPD & 225 & 50 & $22.2 \%$ & $00: 46: 43$ & 2 & Yes \\
\hline 2-s CPD & 261 & 77 & $29.5 \%$ & 00:49:59 & 3 & Yes \\
\hline Control & 171 & 170 & $99.4 \%$ & & & No \\
\hline Total/average & $603^{\mathrm{a}}$ & $133^{\mathrm{a}}$ & $18.9 \%^{\mathrm{a}}$ & 02:00:55 & & \\
\hline
\end{tabular}

Rank order is based upon the number of trials to criterion

${ }^{a}$ Total/average data exclude control condition

${ }^{\mathrm{b}}$ Data in parentheses relate to reduced 2-stimuli instruction

\section{Discussion}

The main research questions were to determine the effectiveness and relative efficiency of each instructional condition. All three prompt delay procedures proved effective, and on balance, PPD was more efficient than either CPD procedure. Given the limited evidence in the literature with direct comparison of these procedures, this is useful information about alternate versions of response prompting, a strategy often used during instruction to address problems with behavioral skills deficits that are seen in individuals with ASD/ID.

Present findings show that all three prompt delay conditions proved effective, producing acquisition to mastery criterion level, and as anticipated, mastery was not attained in the control condition by any of the participants. This finding is consistent 


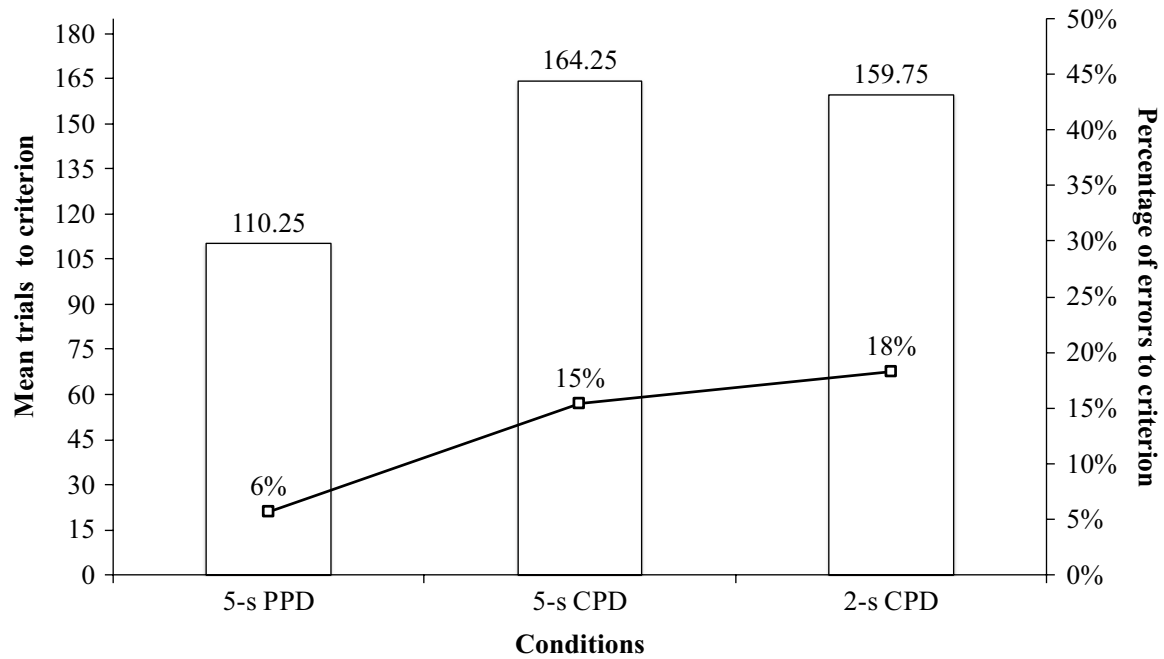

Fig. 2 Mean number of training trials and percentage of errors ( $y$-axis) to mastery criterion for four participants across three instructional conditions and a control ( $x$-axis)

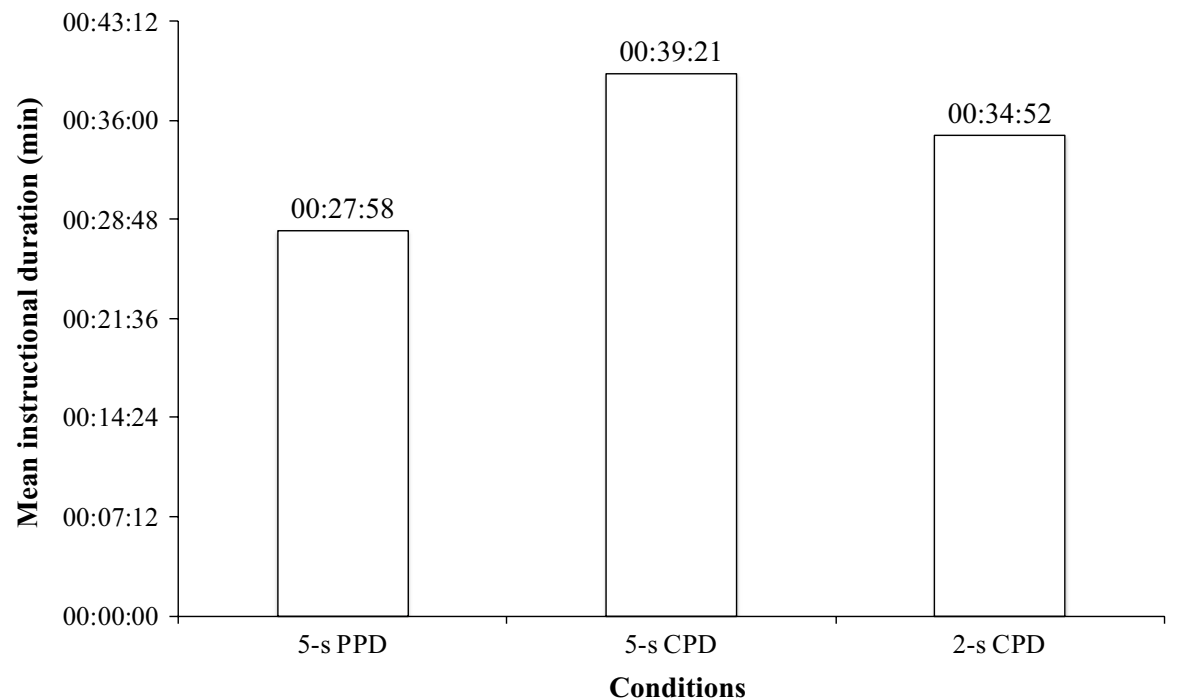

Fig. 3 Mean instructional duration ( $y$-axis) to mastery criterion across four participants for three instructional conditions ( $x$-axis)

with previous research that has shown prompt delay to be an effective instructional procedure in stand-alone investigations (Ault et al. 1988; Doyle et al. 1990; O'Neill et al. 2018; Wolery et al. 1993) and in reviews of the literature (Cengher et al. 2018, 2019; Handen and Zane 1987; Walker 2008; Wolery and Gast 1984; Wolery et al. 1992). When compared with other types of prompt and prompt-fading procedures, 
CPD and PPD have been reported as being as effective as LTM prompting, but more efficient (Bennett et al. 1986; Heckaman et al. 1998; Wolery et al. 1990), whereas MTL prompting is reported as being as effective but more efficient than CPD (Aykut 2012). More recently, PPD has been shown to be as effective as LTM and MTL fading, with the LTM procedure most efficient when compared with both (Schnell et al. 2019; Seaver and Bourret 2014); in one, PPD was the middle-ranked procedure in terms of efficiency (Seaver and Bourret 2014). Looking at a range of prompting strategies, both Seaver and Bourret (2014) and Schnell et al. (2019) concluded that outcomes were associated with variables specific to each learner. Neither study sought to systematically CPD with PPD, but rather sought to identify the optimal instructional procedure for each learner.

Because there is not much time to commit errors and the delay to the prompt is faded gradually, it is more likely that PPD will be an errorless procedure, and this is supported by our findings. In terms of how efficient each procedure was against each other, PPD produced the least mean number of training trials and considerably lower percentage of errors $(6 \%)$, in comparison with 5-s (15\%) and 2-s CPD (18\%, Fig. 2). At the individual level, with Seamus, Cian, and Eimear, 5-s PPD was ranked first in terms of the least number of training trials to mastery, and second on this measure for Cahil. Cahil was also the participant for whom the procedure had to be modified to reduce its difficulty before mastery was reached with any of the prompting procedures, and he had the lowest scores on ability measures (see Table 1), so it may be that he was at the margin of the ability range where these procedures can be used effectively. This study also measured duration of instructional time to criterion (Fig. 3), and mean instructional duration was also lowest with progressive prompt delay. Thus, on almost all efficiency measures for the participants included here, the 5-s PPD was the most efficient prompt-fading procedure. This is consistent with the findings of O'Neill et al. (2018) where for three out of four of their participants, PPD was most efficient when compared with 2-s and 5-s CPD, producing acquisition to mastery criterion in the least mean number of training trials while producing the least percentage of errors to criterion. The present study adds to the body of evidence in support of using the 5-s PPD, not least because duration of instruction to mastery was also less than both CPD conditions. As noted above, for one participant across these two studies, 5-s PPD was not ranked first. Additionally, training stimuli had to be reduced from three to two for that participant before mastery was achieved. These findings chime with the inconsistencies in the literature in relation to the efficiency of outcomes of the many instructional procedures used for persons with ASD/ID, and this is perhaps related to the intrinsic heterogeneity found in this group (Ault et al. 1988; Cengher et al. 2018, 2019, 2016; Libby et al. 2008; O'Neill et al. 2018; Schnell et al. 2019; Seaver and Bourret 2014; Walker 2008; Wolery and Gast 1984).

It is perhaps not surprising that PPD was associated with the least number of errors. At the beginning of PPD training, the opportunity to engage in an independent learner response is limited to $1 \mathrm{~s}$, then $2 \mathrm{~s}$, and so on. Because duration of time available to respond independently only increases contingent on correct learner responses in the previous session, learners are only given more time to respond when correct independent responses have become more likely; the procedure is therefore 
responsive to learner's performance as the delay to prompt will decrease should the learner falter. This incremental approach appeared to benefit the learners within this study (as in O'Neill et al. 2018). With the CPD procedures, in contrast, there is more time to respond from the outset of training and therefore more time to commit an error. This is likely why CPD was associated with a higher percentage of errors. This factor is particularly important at the beginning of instruction, when more errors are likely to occur. It is expected that as instruction progresses the prompt will not be necessary, being replaced with independent responding. In the present procedure, prompted and independent correct responses were not differentially reinforced (i.e., both were followed by the same reinforcer) except that independent correct responses resulted in a shorter delay between trial onset and reinforcement. This procedural variation did ensure that reinforcement during instruction was high, and as performance improved, prompted correct responses became rare.

The issue of errors during instruction has previously been identified as important by Green (2001), as too high error rate may contribute to the development of faulty stimulus control. Current evidence tentatively suggests that PPD may be a wise first choice when deciding among prompt delay procedures. However, this conclusion would be strengthened if the advantage of PPD was replicated in another laboratory.

\section{Limitations and Directions for Future Research}

The present findings could be strengthened and clarified in future research if some limitations of the present study were addressed. The adapted alternating treatment design does not require any baseline data with recommendations suggesting just one or two sessions be conducted (Gast 2009). These recommendations were followed here, but it can be argued that stronger conclusions can be drawn if the baseline phase is continued for at least three sessions in each condition to detect any possible trend. During instruction conditions, participants accessed the programmed consequence contingent on correct independent or correct prompted responses. The absence of differential reinforcement for independent responding (except, as noted, through earlier delivery of the reinforcer) may have slowed down the transfer of stimulus control from the prompt to the programmed discriminative stimulus, so the inclusion of that contingency should be considered. The PI check highlighted some errors of omission for one participant. PI scores drop as soon as one step of a sequence is in error. In this case, on a few occasions the experimenter either observed a longer delay value than was prescribed for that instructional step and condition or failed to record a correct learner response when one had occurred. This resulted in a slightly lower average PI score across participants and represents a limitation of the present study.

This study, and a previous related one in a similar school setting (O'Neill et al. 2018), targeted academic skills. It would be useful if future attempts at replication included functional skills, such as demonstrating a preference between activities, identifying types of money, or toothbrushing skills, to see whether results are generalizable to those types of skills, as these are often targeted by behavior analysts. Relatedly, this study was entirely conducted within the school setting, 
so generalization to other contexts (e.g., home, or community) was not assessed. Finally, inclusion of a social validity measure to assess type of the instruction the learners prefer, and which procedures special educators are able to implement, would be useful.

\section{Implications for Practice}

It is important for clinicians to have an evidence base that may be used to inform instructional decision making (Odom et al. 2010). Comparisons that include efficiency measures like the ones used here extend the data available beyond that of effectiveness.

While all three prompt delay procedures proved effective, on balance, PPD was more efficient than either CPD procedure. As in the previous research, there was some variation in the outcome across individuals, with the three higher-functioning individuals showing more consistent findings. Nonetheless, the sum of evidence of this and previous research (O'Neill et al. 2018) may support selection of PPD as a wise option as first choice by clinicians.

Acknowledgements The authors would like to acknowledge the assistance of those who conducted IOA and PI checks of experimental sessions. Funding was provided through a Department for Employment and Learning PhD Studentship, Northern Ireland, to the first author. That body was not involved in the design or execution of this study. Consent to conduct this experiment was granted by the University's Research Ethics Committee. Furthermore, informed consent and assent were obtained from the participants' parents and participants themselves, respectively.

\section{Compliance with Ethical Standards}

Conflict of interest The authors declare that they have no conflicts of interest.

Open Access This article is licensed under a Creative Commons Attribution 4.0 International License, which permits use, sharing, adaptation, distribution and reproduction in any medium or format, as long as you give appropriate credit to the original author(s) and the source, provide a link to the Creative Commons licence, and indicate if changes were made. The images or other third party material in this article are included in the article's Creative Commons licence, unless indicated otherwise in a credit line to the material. If material is not included in the article's Creative Commons licence and your intended use is not permitted by statutory regulation or exceeds the permitted use, you will need to obtain permission directly from the copyright holder. To view a copy of this licence, visit http://creativecommons.org/licen ses/by/4.0/.

\section{References}

Ault, M. J., Gast, D. L., \& Wolery, M. (1988). Comparison of progressive and constant time-delay procedures in teaching community-sign word reading. American Journal on Mental Retardation, 93(1), 11-56.

Aykut, Ç. (2012). Effectiveness and efficiency of constant-time delay and most-to-least prompt procedures in teaching daily living skills to children with intellectual disabilities. Educational Sciences: Theory \& Practice, 12(1), 366-373. 
Ayres, K. M., \& Gast, D. L. (2009). Dependent measures and measurement procedures. In D. L. Gast (Ed.), Single subject research methodology in behavioural sciences (pp. 129-165). New York, London: Routledge, Taylor and Francis. https://doi.org/10.4324/9780203877937.

Bennett, D. L., Gast, D. L., Wolery, M., \& Schuster, J. W. (1986). Time delay and system of least prompts: A comparison in teaching manual sign production. Education and Training of the Mentally Retarded, 21, 117-129.

Billingsley, F. F., White, O., \& Munson, R. (1980). Procedural reliability: A rationale and an example. Behavioral Assessment, 2, 229-241.

Carr, E. G., \& Durand, V. (1985). Reducing behavior problems through functional communication training. Journal of Applied Behavior Analysis, 2(2), 111-126.

Cengher, M., Budd, A., Farrell, N., \& Fienup, D. M. (2018). A review of prompt-fading procedures: Implications for effective and efficient skill acquisition. Journal of Developmental and Physical Disabilities, 30(2), 155-173. https://doi.org/10.1007/s10882-017-9575-8.

Cengher, M., Kim, J. Y., \& Fienup, D. M. (2019). A review of prompt-fading procedures, part II: Parameters and components. Journal of Developmental and Physical Disabilities. https://doi.org/10.1007/ s10882-019-09711-2.

Cengher, M., Shamoun, K., Moss, P., Roll, D., Feliciano, G., \& Fienup, D. M. (2016). A comparison of the effects of two prompt-fading strategies on skill acquisition in children with autism spectrum disorders. Behavior Analysis in Practice, 9, 115-125. https://doi.org/10.1007/s40617-015-0096-6.

Coleman-Martin, M. B., \& Heller, K. W. (2004). Using a modified constant prompt-delay procedure to teach spelling to students with physical disabilities. Journal of Applied Behavior Analysis, 37(4), 469-480. https://doi.org/10.1901/jaba.2004.37-469.

Coon, J. T., \& Miguel, C. F. (2012). The role of increased exposure to transfer-of-stimulus-control procedures on the acquisition of intraverbal behavior. Journal of Applied Behavior Analysis, 45(4), 657666. https://doi.org/10.1901/jaba.2012.45-657.

DeLeon, I. G., \& Iwata, B. A. (1996). Evaluation of a multiple-stimulus presentation format for assessing reinforcer preferences. Journal of Applied Behavior Analysis, 29(4), 519-532. https://doi.org/10.1901/ jaba.1996.29-519.

Demchak, M. (1990). Response prompting and fading methods: A review. American Journal on Mental Retardation, 94(6), 603-615.

Doyle, P. M., Wolery, M., Gast, D. L., Ault, M. J., \& Wiley, K. (1990). Comparison of constant time delay and the system of least prompts in teaching preschoolers with developmental delays. Research in Developmental Disabilities, 11(1), 1-22. https://doi.org/10.1016/0891-4222(90)90002-P.

Etzel, B. C., \& LeBlanc, J. M. (1979). The simplest treatment alternative: The law of parsimony applied to choosing appropriate instructional control and errorless-learning procedures for the difficult-to-teach child. Journal of Autism and Developmental Disorders, 9(4), 361-382.

Fisher, W. W., Retzlaff, B. J., Akers, J. S., DeSouza, A. A., Kaminski, A. J., \& Machado, M. A. (2019). Establishing initial auditory-visual conditional discriminations and emergence of initial tacts in young children with autism spectrum disorder. Journal of Applied Behavior Analysis, 52(4), 1089-1106. https ://doi.org/10.1002/jaba.586.

Gast, D. L. (2009). Single subject research methodology in behavioral sciences. New York and London: Routledge, Taylor and Francis. https://doi.org/10.4324/9780203877937.

Green, G. (2001). Behavior analytic instruction for learners with autism: Advances in stimulus control technology. Focus on Autism and Other Developmental Disabilities, 16(2), 72-85. https://doi. org/10.1177/108835760101600203.

Halbur, M. E., Kodak, T., Wood, R., \& Corrigan, E. (2019). An evaluation of parent preference for prompting procedures. Journal of Applied Behavior Analysis, 9999, 1-20. https://doi.org/10.1002/jaba.616.

Handen, B. L., \& Zane, T. (1987). Delayed prompting: A review of procedural variations and results. Research in Developmental Disabilities, 8(2), 307-330. https://doi.org/10.1016/0891-4222(87)90010 -2 .

Hanley, G. P., Iwata, B. A., \& McCord, B. E. (2003). Functional analysis of problem behavior: A review. Journal of Applied Behavior Analysis, 36(2), 147-185. https://doi.org/10.1901/jaba.2003.36-147.

Heal, N. A., Hanley, G. P., \& Layer, S. (2009). An evaluation of the relative efficacy of children's preferences for teaching strategies that differ in amount of teacher directedness. Journal of Applied Behavior Analysis, 42(1), 123-143. https://doi.org/10.1901/jaba.2009.42-123.

Heckaman, K., Alber, S., Hooper, S., \& Heward, W. (1998). A comparison of least-to-most prompts and progressive time delay on the disruptive behavior of students with autism. Journal of Behavioral Education, 8(2), 171-201. https://doi.org/10.1023/A:1022883523915. 
Libby, M. E., Weiss, J. S., Bancroft, S., \& Ahearn, W. H. (2008). A comparison of most-to-least and leastto-most prompting on the acquisition of solitary play skills. Behavior Analysis In Practice, 1(1), 37-43. https://doi.org/10.1007/BF03391719.

MacDuff, G. S., Krantz, P. J., \& McClannahan, L. E. (1993). Prompts and prompt-fading strategies for people with autism. In Making a difference: Behavioral intervention for autism (pp. 37-50). Retrieved from http://dddc.rutgers.edu/pdf/prompting.pdf.

National Autism Center. (2009). National Standards Project: Addressing the need for evidence-based practice guidelines for autism spectrum disorders. Randolph, MA: National Autism Center.

National Autism Center. (2015). Findings and conclusions: National Standards Project-Phase 2. Randolph, MA: National Autism Center.

O'Neill, S. J., McDowell, C., \& Leslie, J. C. (2018). A comparison of prompt delays with trial-anderror instruction in conditional discrimination training. Behavior Analysis in Practice. https://doi. org/10.1007/s40617-018-0261-9.

Odom, S. L., Collet-Klingenberg, L., Rogers, S. J., \& Hatton, D. D. (2010). Evidence-based practices in interventions for children and youth with autism spectrum disorders. Preventing School Failure: Alternative Education for Children and Youth, 54(4), 275-282. https://doi.org/10.1080/104598810037855 06.

Odom, S. L., \& Strain, P. S. (2002). Evidence-based practice in early intervention/early childhood special education: Single-subject design research. Journal of Early Intervention. https://doi.org/10.1177/10538 1510202500212 .

Reichow, B., \& Wolery, M. (2011). Comparison of progressive prompt delay with and without instructive feedback. Journal of Applied Behavior Analysis, 44(2), 327-340. https://doi.org/10.1901/ jaba.2011.44-327.

Robinson, P. W., \& Storm, R. H. (1978). Effects of error and discrimination acquisition on reversal learning. Journal of the Experimental Analysis of Behavior, 29(3), 517-525.

Roncati, A. L., Souza, A. C., \& Miguel, C. F. (2019). Exposure to a specific prompt topography predicts its relative efficiency when teaching intraverbal behavior to children with autism spectrum disorder. Journal of Applied Behavior Analysis, 52(3), 739-745. https://doi.org/10.1002/jaba.568.

Schilmoeller, G. L., Schilmoeller, K. J., Etzel, B. C., \& LeBlanc, J. M. (1979). Conditional discrimination after errorless and trial-and-error training. Journal of the Experimental Analysis of Behavior, 31(3), 405-420. https://doi.org/10.1901/jeab.1979.31-405.

Schnell, L. K., Vladescu, J. C., Kisamore, A. N., DeBar, R. M., Kahng, S., \& Marano, K. (2019). Assessment to identify learner-specific prompt and prompt-fading procedures for children with autism spectrum disorder. Journal of Applied Behavior Analysis, 00(00), 1-19. https://doi.org/10.1002/jaba.623.

Seaver, J. L., \& Bourret, J. C. (2014). An evaluation of response prompts for teaching behavior chains. Journal of Applied Behavior Analysis, 4(4), 1-16. https://doi.org/10.1002/jaba.159.

Sindelar, P., Rosenberg, M., \& Wilson, R. (1985). An adapted alternating treatments design for instructional research. Education \& Treatment of Children, 8(1), 67-76.

Snell, M. E. (1982). Analysis of time delay procedures in teaching daily living skills to retarded adults. Analysis and Intervention in Developmental Disabilities, 2(2-3), 139-155. https://doi.org/10.1016/02704684(82)90015-5.

Snell, M. E., \& Gast, D. L. (1981). Applying time delay procedure to the instruction of the severely handicapped. Research and Practice for Persons with Severe Disabilities, 6(3), 3-14. https://doi. org/10.1177/154079698100600301.

Terrace, H. S. (1963). Discrimination learning with and without "errors". Journal of the Experimental Analysis of Behavior, 6, 1-27. https://doi.org/10.1901/jeab.1963.6-1.

Thomas, P. L. (1989). A comparison of constant and progressive time delay in teaching oral sight reading. Lexington: University of Kentucky.

Touchette, P. E. (1968). The effects of graduated stimulus change on the acquisition of a simple discrimination in severely retarded boys. Journal of the Experimental Analysis of Behavior, 11(1), 39-48. https:// doi.org/10.1901/jeab.1968.11-39.

Touchette, P. E. (1971). Transfer of stimulus control: Measuring the moment of transfer. Journal of the Experimental Analysis of Behavior, 15(3), 347-354. https://doi.org/10.1901/jeab.1971.15-347.

Touchette, P. E., \& Howard, J. S. (1984). Errorless learning: Reinforcement contingencies and stimulus control transfer in delayed prompting. Journal of Applied Behavior Analysis, 17(2), 1307932. https://doi. org/10.1901/jaba.1984.17-175. 
Walker, G. (2008). Constant and progressive time delay procedures for teaching children with autism: A literature review. Journal of Autism and Developmental Disorders, 38(2), 261-275. https://doi.org/10.1007/ s10803-007-0390-4.

Weeks, M., \& Gaylord-Ross, R. J. (1981). Task difficulty and aberrant behavior in severely handicapped students. Journal of Applied Behavior Analysis, 14(4), 449-463. https://doi.org/10.1901/jaba.1981.14-449.

Williams, K. T. (2007). The expressive vocabulary test (2nd ed.). London: Pearson Education.

Wolery, M., Ault, M. J., Gast, D. L., Munson-Doyle, P., \& Griffen, A. (1990). Comparison of constant time delay and the system of least prompts in teaching chained tasks. Education and Training of the Mentally Retarded, 25, 243-257.

Wolery, M., \& Gast, D. L. (1984). Effective and efficient procedures for the transfer of stimulus control. Topics in Early Childhood Special Education, 4(3), 52-77. https://doi.org/10.1177/027112148400400305.

Wolery, M., Holcombe, A., Cybriwsky, C., Doyle, P. M., Schuster, J. W., Ault, M. J., et al. (1992). Constant time delay with discrete responses: A review of effectiveness and demographic, procedural, and methodological parameters. Research in Developmental Disabilities, 13(3), 239-266. https://doi. org/10.1016/0891-4222(92)90028-5.

Wolery, M., Munson-Doyle, P. M., Gast, D. L., Ault, M. J., \& Simpson, S. L. (1993). Comparison of progressive time delay and transition-based teaching with preschoolers who have developmental delays. Journal of Early Intervention, 17(2), 160-176. https://doi.org/10.1177/105381519301700207.

Wong, C., Odom, S. L., Hume, K., Cox, A. W., Fettig, A., Kucharczyk, S., et al. (2015). Evidence-based practices for children, youth, and young adults with autism spectrum disorder: A comprehensive review. Journal of Autism and Developmental Disorders, 45(7), 1951-1966. https://doi.org/10.1007/s1080 3-014-2351-z.

Publisher's Note Springer Nature remains neutral with regard to jurisdictional claims in published maps and institutional affiliations. 